\title{
Tip 2 diabetik hastalarda ortalama trombosit hacmi: mikrovasküler komplikasyonlar ile ortalama trombosit hacmi arasında bir ilişki var mı?
}

\author{
Mean platelet volume in type 2 diabetic patient: is there a relationship \\ between mean platelet volume and diabetic microvascular complications?
}

\author{
Kenan ÇADIRCI ${ }^{1 *}$, Osman Okan OLCAYSU ${ }^{2}$, Derman YiĞiT ${ }^{3}$, Ayşe ÇARLIOĞLU ${ }^{4}$, Şenay ARIKAN ${ }^{5}$ \\ 'Bölge Eğitim ve Araştırma Hastanesi, Iç Hastalıkları Kliniği, Erzurum \\ ${ }^{2}$ Bölge Eğitim ve Araştırma Hastanesi, Göz Kliniği, Erzurum \\ ${ }^{3}$ Bölge Eğitim ve Araştırma Hastanesi, Nöroloji Kliniği, Erzurum \\ ${ }^{4}$ Bölge Eğitim ve Araştırma Hastanesi, Endokrinoloji ve Metabolizma Hastalıkları Kliniği, Erzurum \\ ${ }^{5}$ Kırıkkale Üniversitesi, İç Hastalıkları ABD, Endokrinoloji ve Metabolizma Hastalıkları Kliniği, Kırıkkale
}

\section{öz}

Amaç: Diabetik hastaların çoğunda vasküler trombotik ve aterosklerotik komplikasyonlar görülür. Diabetik hastalarda trombosit boyutundaki değişiklikler aterosklerotik komplikasyonlar ile ilişkilidir. Bu çalışmanın amacı, tip 2 diabetik hastalarda ortalama trombosit hacmi (Mean Platelet Volume, MPV) ile mikrovasküler komplikasyonlar arasındaki ilişkiyi saptamaktır.

Gereç ve Yöntemler: Bu çalışmaya 115 tip 2 DM tanılı hasta (ortalama yaş $50.4 \pm 9.9 \mathrm{yll}$ ve BMI $31.0 \pm 5.3 \mathrm{~kg} / \mathrm{m}^{2}$ ) ve tamamen sağlıklı ve sistemik hastalığı bulunmayan 67 kişide (ortalama yaş $48.8 \pm 12.0$ yıl ve BMI $30.3 \pm 7.3 \mathrm{~kg} / \mathrm{m}^{2}$ ) kontrol grubu olarak dahil edildi. Diabetik grupta kronik diabetik mikrovasküler komplikasyonlar araştırıldı. Nörolojik değerlendirme, oküler fundus muayenesi ve EMG (Elektromyografi) yapıldı. Diabetik hastalarımız öncelikle en az bir mikrovasküler komplikasyonu olan ve olmayan şeklinde ikiye ayrıldı. Daha sonra mikrovasküler komplikasyonu olan hastalar nefropati, nöropati ve retinopatiye göre alt gruplara ayrıldı. Tüm alt gruplarda MPV düzeyi tekrar analiz edildi.

Bulgular: En az bir mikrovasküler komplikasyonu olan diabetik hasta grubumuzda 79 hasta mevcutdu. Bu grup da, 44 (\%34.7) hastada nöropati, 33 (\%26.0) hastada diabetik nefropati ve 13 (\%10.2) hastada ise diabetik retinopati tespit edildi. Mikrovasküler komplikasyonu olmayan diabetik hasta grubunda ise 36 kişi mevcutdu. Bu grup ise diabetik kontrol grubu olarak kabul edildi.

Diabetik mikrovasküler grupta MPV düzeyleri sağlıklı kontrol grubundan anlamlı olarak yüksekti (sırasıyla $8.6 \pm 0.8 \mathrm{fL}$ ve $7.9 \pm 0.8 \mathrm{fL}, \mathrm{p}<0.001)$. Yine diabetik kontrol grubu ile sağlıklı kontrol grupları arasında da MPV düzeyi açısından anlamlı fark mevcutdu ( $8.3 \pm 0.5 \mathrm{fL}$ ve $7.9 \pm 0.8 \mathrm{fL}, \mathrm{p}=0.005)$. Diabetik mikrovasküler grup ile diabetik kontrol grubu arasında ise MPV düzeyleri bakımından fark tespit edilmesine rağmen bu fark istatistiki olarak anlamlı değildi (sırasıyla $8.6 \pm 0.8 \mathrm{fL}$ ve $8.3 \pm 0.5 \mathrm{fL} p=0.06$ ).

Subgrup analizlerinde MPV düzeyleri açısından diabetik nefropati ile sağlıkı kontrol grubu arasında $(p=0.006)$, diabetik nöropati grubu ile sağlıklı kontrol grubu arasında $(p=0.001)$ ve diabetik retinopatili hasta grubu ile sağlıklı kontrol grubu arasında MPV bakımından istatistiki açıdan anlamlı bir fark tespit edildi ( $p=0.02$ ).

Sonuç: Çalışmamızda, Tip 2 DM hasta grubu MPV düzeyinin sağlıklı kontrollere göre istatistiki açıdan anlamlı yüksek olduğunu tespit ettik. Yine diabetik nefropati, diabetik nöropati ve diabetik retinopatiye sahip hastalarda MPV düzeyinin sağlıkı bireylerden daha yüksek olduğunu tespit ettik. Sıklıkla trombosit aktivitesinin bir göstergesi olarak kullanılmakta olan MPV, tip 2 diabetli hastalarda mikrovasküler komplikasyon gelişmesi riski ile ilişkili olabilir.

Anahtar kelimeler: Ortalama trombosit hacmi, diabetik nefropati, diabetik nöropati, diabetik retinopati

Sorumlu Yazar*: Kenan ÇADIRCI, Bölge Eğitim ve Araştırma Hastanesi, lç Hastalıkları Kliniği, Erzurum

E-Posta: doktorcadirci@hotmail.com

Received 21.05.2017 accepted 12.10.2017

Doi: $10.18663 /$ tjcl.315153 


\begin{abstract}
Aim: Most diabetic patients suffer from vascular thrombotic and atherosclerotic complications. Alteration in platelet size are associated with atherosclerotic complications in patients with diabetes. The aim of present study is to determine the relationship between mean platelet volume (MPV) and microvascular diabetic complications in type 2 diabetic patients.
\end{abstract}

Material and Methods: 115 type 2 diabetic patients [mean age $50.4 \pm 9.9$ year and body mass index (BMI) $31.0 \pm 5.3 \mathrm{~kg} /$ $\mathrm{m}^{2}$ ], and 67 healthy control subjects without any systemic disease (mean age $48.8 \pm 12.0$ year and BMI $30.3 \pm 7.3 \mathrm{~kg} / \mathrm{m}^{2}$ ) were included in this study. Chronic diabetic microvascular complications in diabetic group were researched. Neurological evaluation, ocular fundus examination and EMG (electromyography) were performed. Our diabetic patients were initially divided into two groups with and without at least one microvascular complication. Subsequently, patients with microvascular complications were divided into subgroups according to nephropathy, neuropathy and retinopathy. MPV levels were re-analyzed in all subgroups.

Results: There were 79 patients in our diabetic patient group with at least one microvascular complication. In this group, 44 (34.7\%) patient neuropathy, 33 (26.0\%) patients diabetic nephropathy and 13 (10.2\%) patients diabetic retinopathy were detected. There were 36 patients in the diabetic group without microvascular complications. This group was accepted as a diabetic control group.

We determined that mean MPV levels in diabetic microvascular group was significantly different from control group $(8.6 \pm 0.8 \mathrm{fL}$ and $7.9 \pm 0.8 \mathrm{fL}, \mathrm{p}<0.001)$. Again we determined that mean MPV levels in diabetic control group was significantly different from control group $(8.3 \pm 0.5 \mathrm{fL}$ ve $7.9 \pm 0.8 \mathrm{fL}, \mathrm{p}=0.005)$

Despite the difference in MPV between the diabetic microvascular group and the diabetic control group, this difference was not statistically significant ( $8.6 \pm 0.8 \mathrm{fL}, 8.3 \pm 0.5 \mathrm{fL}, \mathrm{p}=0.06$ ).

In subgroup analysis, we demonstrated that mean MPV levels in diabetic nephropathy $(\mathrm{p}=0.006)$ and in diabetic neuropathy groups ( $p=0.001$ ) and diabetic retinopathy group ( $p=0.02$ ) were higher than control subjects.

Conclusions: In our study, we determined mean MPV levels in type 2 diabetic group was significantly highly from control group. Also, we detected MPV level in diabetic patients with nephropathy, neuropathy and retinopathy is more increase than healthy subjects. Although MPV is often used as the marker of platelet activity, elevated MPV levels in patients with type 2 diabetes mellitus may associate with increased microvascular complication risk.

Key words: Mean platelet volume, diabetic nephropathy, diabetic neuropathy, diabetic retinopathy

\section{Giriş}

Diabetes Mellitus, kronik hiperglisemi ile seyreden, mikrovasküler ve makrovasküler komplikasyonları ile önemli morbidite ve mortaliteye neden olan bir karbonhidrat metabolizma bozukluğudur. Glukozun damar endotelini hedef alan toksisitesi ile kronik süreçte trombosit aktivasyonu oluşmakta ve trombojenik olaylara eğilim artmaktadır. Bu patojenik mekanizma ile oluşan mikrovasküler ve makrovasküler komplikasyonlar, hastanın morbiditesini artırmakta ve tedavisini güçleştirmektedir.

Ortalama trombosit hacminin otomatik analizörler yardımı ile ölçülen bir değeri olan MPV (Mean Platelet Volume, Ortalama Trombosit Hacmi) son yıllarda trombosit fonksiyonlarının bir göstergesi olarak kabul edilen, kolay ölçülebilen bir değer olarak tespit edilmiştir.

Invitro aggregometri yöntemi ile yapılan değerlendirmede büyük plateletlerin küçük olanlara göre enzimatik ve metabolik olarak daha aktif oldukları tespit edilmiştir ve bu durumun daha yüksek bir trombotik risk taşıdığı aşikardır (1).
Platelet morfoloji ve fonksiyonlarındaki değişiklikler, mikrovasküler ve makrovasküler hastalıklar için risk faktörü olarak düşünülebilir (2).

Bu çalışmanın amacı, tip 2 diabetik hastalarda ortalama trombosit hacmi (Mean PlateletVolume, MPV) ile mikrovasküler komplikasyonlar arasındaki ilişkiyi saptamaktır.

\section{Gereç ve Yöntemler}

Çalışmaya Erzurum Bölge Eğitim ve Araştırma Hastanesi Endokrinoloji ve Metabolizma hastalıkları polikliniğinde Tip2 DM tanısı ile takip edilen ve herhangi bir karaciğer ve böbrek yetmezliği ile trombosit hacmini değiştiren kan diskrazisi gibi hastalığı olmayan, trombosit sayısı normal aralıkta tespit edilen ve trombosit fonksiyonlarını bozan herhangi bir ilaç kullanım öyküsü olmayan 115 hasta ve herhangi bir sistemik hastalığı olmayan tamamen sağlıklı ve yine trombosit fonksiyonlarını bozan herhangi bir ilaç kullanım öyküsü olmayan 67 kişide kontrol grubu olarak alındı. Diabetik hasta grubunda yer alan kişilerin son 6 ay içerisinde MPV düzeyini etkileyebilecek antihiperlipidemik ve antiagregan ilaç kullanmamış olmasına dikkat edildi. Her iki grup arasında yaş, cinsiyet, vücut kitle 
indeksi bakımından istatistiki anlamlı bir fark tesit edilemedi.

Bütün venöz kan örnekleri 12 saatlik açlık sonrası antekübital venden alındı. Çalışmada tam kan sayımı analizi, otomatik hematoloji analizörü Beckman Coulter LH 750 (Beckman Coulter, ABD) ile gerçekleştirildi. Trombosit sayısı $(P C)$ ve ortalama trombosit hacmi (MPV) ölçüldü.

İstatistiksel analiz için SPSS 19 programı kullanıldı. Bütün sonuçlar ortalama \pm standart deviasyon (SD) olarak ifade edildi. Kontrol ve hasta gruplar arası karşılaştırma için independent-t testi kullanıldı. Değişkenlerin değerlendirilmesinde Pearson's korelasyon testi kullanıldı. $p<0.05$ değeri istatistiki açıdan anlamlı olarak kabul edildi.

\section{Bulgular}

Çalışmaya Tip 2 DM tanısı ile tedavi almakta olan (hastalar arasında tedavi, diabet süresi, cinsiyet ayrımı yapılmadan) 115 hasta alındı. Diabetik hastalar mikrovasküler komplikasyonu olup olmama özelliklerine dayanılarak 2 gruba ayrıldı. Diabetik mikrovasküler grupta en az bir diabetik mikrovasküler komplikasyonu olan 79 hasta (32 erkek, 47 bayan) ve diabetik kontrol grubunda ise herhangi bir mikrovasküler komplikayonu olmayan 36 diabetik hasta (19 erkek, 17 bayan) çalışmaya dahil edildi. Aynı zamanda herhangi bir sistemik hastalığı olmayan 67 kişide (30 erkek, 37 bayan) sağlıklı kontrol grubu olarak alındı.

Tip 2 DM grubunda yer alan hastaların yaş ortalaması 50.4 \pm 9.9 yıl ve BMI $31.0 \pm 5.3 \mathrm{~kg} / \mathrm{m}^{2}$ ve kontrol grubunun ise ortalama yaş $48.8 \pm 12.0 \mathrm{yll}$ ve BMI $30.3 \pm 7.3 \mathrm{~kg} / \mathrm{m}^{2}$ olarak hesaplandı. Her iki grup arasında yaş ve BMI yönü ile istatistiki açıdan anlamlı bir fark tespit edilemedi. Sırası ile p değerleri 0.3 ve 0.5 olarak hesaplandı. Tip2 DM grubuna ait MPV ortalaması $8.5 \pm 0.7 f L$ ve kontrol grubuna ait MPV ortalaması ise $7.9 \pm 0.8 \mathrm{fL}$ olarak tespit edildi. Aralarında istatistiki açıdan anlamlı bir fark olduğu tespit edildi ( $p<0.001)$.

Diabetik mikrovasküler grupta MPV düzeyleri sağlıklı kontrol grubundan anlamlı olarak yüksekti (sırasıyla $8.6 \pm 0.8 \mathrm{fL}$ ve $7.9 \pm 0.8 \mathrm{fL}$, $p<0.001)$. Yine diabetik kontrol grubu ile sağlıklı kontrol grupları arasında da MPV düzeyi açısından anlamlı fark mevcutdu (sırasıyla $8.3 \pm 0.5 \mathrm{fL}$ ve $7.9 \pm 0.8 \mathrm{fL}, \mathrm{p}=0.005$ ). Diabetik mikrovasküler grup ile diabetik kontrol grubu arasında ise MPV düzeyleri bakımından fark tespit edilmesine rağmen bu fark istatistiki olarak anlamlı değildi (sırasıyla 8.6 $\pm 0.8 \mathrm{fL}$ ve $8.3 \pm 0.5 \mathrm{fL} p=0.06$ ).

Hasta ve kontrol gruplarına ait demografik veriler Tablo 1' de gösterilmiştir.

\begin{tabular}{|c|c|c|c|c|c|c|}
\hline & \multicolumn{2}{|c|}{ DMTip2 } & \multirow[t]{2}{*}{ Sağlıklı Kontrol } & \multirow{2}{*}{ p1 } & \multirow{2}{*}{ p2 } & \multirow{2}{*}{ p3 } \\
\hline & Mikrovasküler & Diabetik kontrol & & & & \\
\hline Hasta sayısı & 79 & 36 & 67 & & & \\
\hline Cinsiyet ( E/K) & $32 / 47$ & $19 / 17$ & $30 / 37$ & & & \\
\hline Yaş (yll) & $51.0 \pm 10.8$ & $49.3 \pm 7.3$ & $48.8 \pm 12.0$ & 0.25 & 0.74 & 0.28 \\
\hline BMI $\left(\mathbf{k g} / \mathrm{m}^{2}\right)$ & $31.0 \pm 5.5$ & $31.0 \pm 4.9$ & $30.3 \pm 7.3$ & 0.67 & 0.43 & 0.68 \\
\hline 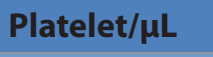 & $267.4 \pm 71,6$ & $288.9 \pm 66.7$ & $233.7 \pm 8.8$ & 0.7 & 0.6 & 0.4 \\
\hline MPV(fL) & $8.6 \pm 0.8$ & $8.3 \pm 0.5$ & $7.9 \pm 0.8$ & $<0.001 *$ & $0.005^{*}$ & 0.06 \\
\hline CRP & $0.7 \pm 1.05$ & $0.7 \pm 0.9$ & $0.6 \pm 0.9$ & 0.9 & 0.4 & 0.3 \\
\hline Ferritin & $95.5 \pm 98.5$ & $88.2 \pm 88.8$ & $88.8 \pm 82.8$ & 0.4 & 0.3 & 0.6 \\
\hline Fibrinojen & $348.2 \pm 81.9$ & $320.1 \pm 80.9$ & $332.2 \pm 77.7$ & 0.08 & 0.06 & 0.7 \\
\hline \multicolumn{7}{|c|}{$\begin{array}{l}\text { *Diabetik mikrovasküler grup ile sağlıklı kontrol arasındaki istatistiki ilişki p1 } \\
\text { *Diabetik kontrol grubu ile sağlıklı kontrol arasındaki istatistiki ilişki p2 } \\
\text { *Diabetik mikrovasküler grup ile diabetik kontrol grubu arasındaki istatistiki il }\end{array}$} \\
\hline
\end{tabular}

Çalışmaya alınan diabetik mikrovasküler grupta yer alan 79 hasta içerisinde birden fazla sayıda mikrovasküler komplikasyonu olanlar, subgrup analizlerinde bulundurdukları komplikasyon türüne göre birden fazla gruba dahil edilerek subgrup analizleri yapıldı. Buna göre diabetik mikrovasküler grupta 44 (\%34.7) hastada nöropati, 33 (\% 26.0) hastada diabetik nefropati ve 13 (\%10.2) hastada ise diabetik retinopati tespit edildi.
Subgrup analizlerinde MPV düzeyleri açısından diabetik nefropati ile sağlıklı kontrol grubu arasında $(p=0.006)$, diabetik nöropati grubu ile sağlıklı kontrol grubu arasında $(p=0.001)$ ve diabetik retinopatili hasta grubu ile sağlıklı kontrol grubu arasında MPV bakımından istatistiki açıdan anlamlı bir fark tespit edildi ( $p=0.02$ ).

Subrupların sağlıklı kontrol grubu ile yapılan karşılaştırmalara ait istatistiki veriler Tablo-2' de gösterilmiştir. 


\begin{tabular}{|l|c|c|c|c|}
\hline Tablo 2: Diabetik Mikrovasküler komplikasyonlara ait veriler \\
\hline $\begin{array}{l}\text { Diabetik } \\
\text { Komplikasyon }\end{array}$ & $\begin{array}{c}\text { Hasta } \\
\text { sayıs }\end{array}$ & $\begin{array}{c}\text { MPV } \\
\text { ( fL) }\end{array}$ & $\begin{array}{c}\text { Sağlıkl } \\
\text { kontrol } \\
\text { p }\end{array}$ & $\begin{array}{c}\text { Diabetik } \\
\text { kontrol } \\
\text { p }\end{array}$ \\
\hline Nefropati & 33 & $8.5 \pm 0.9$ & $\mathbf{0 . 0 0 6 *}$ & $\mathbf{0 , 5}$ \\
\hline Nöropati & 44 & $8.5 \pm 0.8$ & $\mathbf{0 . 0 0 1 *}$ & $\mathbf{0 , 2}$ \\
\hline Retinopati & 13 & $8.5 \pm 0.8$ & $\mathbf{0 . 0 2 *}$ & $\mathbf{0 , 5}$ \\
\hline
\end{tabular}

Yine MPV düzeyleri açısından diabetik mikrovasküler grup ile diabetik kontrol grubu arasında istatistiki karşılaştırma yapılmıştır. Buna gore diabetik nefropati grubu ile diabetik kontrol grubu arasında $(p=0.5)$, diabetik nöropati ile diabetik kontrol grubu arasında $(p=0.2)$ ve diabetik retinopatisi olan grup ile diabetik kontrol grubu arasında $(p=0.5)$ anlamlı istatistiki fark tespit edilememiştir.

Çalışmamızda diabetik grup ile sağlıklı kontrol grubu arasında platelet miktarı, CRP ve fibrinojen düzeyi arasında anlamlı bir fark tespit edilemedi.

\section{Tartışma}

Diabetes Mellitus, dünyada önemli ve artan oranlarda morbidite ve mortalite sebebidir. Diabete eşlik eden hiperglisemi, toksik ara metabolizma ürünleri ve serbest oksijen radikalleri üzerinden tüm vücudu etkileyen patolojik süreçlere yol açar. Hipergliseminin endotel hücrelerine toksisitesi çok iyi bilinmektedir. Bundan dolayı hastalığın ilerleyen dönemlerinde mikrovasküler ve makrovasküler komplikasyonlar oluşmakta ve önemli morbidite ve mortalite sebebi olmaktadır.

Diabetik mikrovasküler komplikasyonlar (retinopati, nöropati ve nefropati) tip2 diabetli 100 milyonlarca hastayı etkilemektedir. Genellikle uzun süredir devam eden ya da kontrol edilemeyen hastalığı olan insanları etkiler, teşhis sırasında tespit edilebileceği gibi teşhis konmamış kişilerde de olabilir (3).

Diabete bağlı olsun veya olmasın, vasküler aterotrombotik olayların fizyopatogenezinde trombositler anahtar rol oynarlar. Bundan dolayı trombosit fonksiyonlarının kolay ölçülebilen bir göstergesi olarak MPV, ilgi odağı olmuştur.

MPV, platelet aktivasyonu ve fonksiyonları için kabul edilen bir indikatördür (4). Daha büyük platletlerin daha genç olduğu, daha reaktif olduğu ve daha hazır oldukları bilinmektedir. Küçük plateletlere göre daha fazla dens granül taşıdıkları, $\beta$ tromboglobulin ve serotonin sekrete ettikleri ve daha fazla tromboxan A2 sentezledikleri bilinmektedir (5).

Literatürde diabetik hastalarda tespit edilen MPV değerlerinin normal sağlıkı bireyler ile karşılaştıııldığı çalışmalar vardır (6-8). Hekimsoy ve arkadaşları tarafından yapılan ve 145 tip 2 DM ve 100 sağlıklı kontrol grubunun dahil edildiği çalışmalarında MPV' nin diabetik grupta non-diabetik gruba kıyasla daha yüksek olduğu ve bunun istatistiki anlamlı olduğu bildirilmiştir (6). Papanas ve arkadaşları tarafından yapılan ve 265 Tip 2 diabetik hastanın alındığı çalışmada MPV kontrol grubuna göre diabetik grupta anlamlı yüksek olarak tespit edilmiştir (7). Yenigün ve arkadaşları da yapmış oldukları ve 48 hasta ve 30 sağlıklı gönüllünün alındığı çalışmalarında diabetik hastalarda MPV değerini non-diabetik gruba göre istatistiki anlamlı yüksek olarak tespit etmişlerdir (8).

Bizim çalışmamızda MPV değerleri, hem Tip2 DM grupta ve hem de Tip2 DM grubu oluşturan mikrovasküler grup ile diabetik kontrol grubunda sağlıklı kontrol grubuna göre istatistiksel olarak anlamlı bir şekilde yüksek bulunmuştur.

Yine mikrovasküler grubu oluşturan alt gruplar olan diabetik nefropati, nöropati ve retinopati grubu MPV ortalamaları, sağlıklı kontrol grubu MPV ortalamasına göre istatistiksel olarak anlamlı bir şekilde yüksek bulunmuştur.

Diyabetin mikrovasküler komplikasyonları ve MPV arasındaki ilişkileri inceleyen pek çok çalışma literatürde dikkati çekmektedir. Bazı çalışmalar MPV' nin mikrovasküler komplikasyonların varlığında arttığını ve anlamlı yükseklikler gösterdiğini ifade ederken $(7,9)$, bazı çalışmalar ise her iki grup arasında anlamlı fark olmadığııı ifade etmektedir $(6,10,11)$.

Ünübol ve arkadaşları yapmış oldukları çalışmalarında, 354 DM tip2 tanılı hastayı mikroalbuminüri pozitif ve negatif gruplara ayırarak, gruplar arasında MPV bakımından fark olup olmadığını araştırmışlardır. Bu çalışmada, 124 mikroalbuminüri pozitif hasta ve 230 mikroalbuminüri negatif hasta çalışmaya dahil edilmiş ve mikroalbuminüri pozitif $\mathrm{DM}^{\prime}$ lu hasta grubu lehine, gruplar arasında MPV bakımından istatistiki fark tespit etmişlerdir (9). Papanas ve arkadaşları tarafından, yine DM Tip2 li hastaların dahil edildiği çalışmalarında ise, diabetik hastalar retinopati ve mikroalbuminüri pozitifliğine göre gruplara ayrılarak değerlendirmeye alınmıştır. Retinopati pozitif grup ile negatif grup arasında pozitif grup lehine ve yine mikroalbuminüri pozitif grup ile mikroalbuminüri negatif grup arasında da pozitif grup lehine ortalama MPV değeri açısından anlamlı yükseklik tespit edilmiştir (7).

Hekimsoy ve arkadaşları tarafından yapılan ve yukarıda bahsettiğimiz çalışmalarında, diabetik hasta MPV değerinin sağlıklı kontrollere göre anlamlı yüksek olduğu tespit edilmiş 
ve MPV' nin hem makrovasküler ve hem de mikrovasküler diabetik komplikasyonun gelişimindeki rolünü tespit etmeye yönelik olarak da alt grup analizleri yapılmıştır. Buna göre diabetik retinopati mikrovasküler ve koroner arter hastalığının ise makrovasküler komplikasyonlara örnek olarak alınarak değerlendirildiği alt grup değerlendirmelerinde, diabetik retinopatili grup ile retinopatisi olmayan diabetik hasta grubu arasında ve yine diabetik koroner kalp hastalığı olan grup ile koroner arter hastalığı olmayan diabetik grup arasında MPV bakımından anlamlı fark tespit edememişlerdir (6). Jindal ve arkadaşlarının yaptıkları ve 75 diabetik (50 hastada en az bir diabetik mikrovasküler komplikasyon mevcut) ve 50 nondiabetik hastanın dahil edildiği çalışmalarında MPV nin diabetik mikrovasküler komplikasyonları olan hastalar ile mikrovasküler komplikasyonu olmayan diabetik grup arasında anlamlı fark göstermediği belirtilmiştir (10). Kebapçılar ve arkadaşları tarafından yapılan ve 48 tip 2DM tanılı hastanın alındığı çalışmalarında, MPV ile diabetik mikrovasküler komplikasyonlar arasında bir ilişki tespit edemediklerini, bu değerlendirmeyi diabetik mikrovaskler komplikasyonu olan hastalar ile komplikasyonu olmayan hastalar arasında yapıldığını belirtmişlerdir (11).

Sadece mikrovasküler komplikasyonlara sahip diabetik hasta gruplarını değerlendirmeye aldığımız çalışmamızda, diabetik mikrovasküler komplikasyonlara sahip bireylerin MPV ortalamasının sağlıklı birey MPV ortalamasından yüksek olduğunu, ama diabetik birey MPV ortalamasından ise istatistiki anlamlı bir fark taşımadığını tespit ettik.

Sonuç olarak MPV sıklıkla trombosit aktivitesinin bir göstergesi olarak kullanılsa da, tip 2 diabetli hastalarda MPV seviyelerinin artması diyabetik mikrovasküler komplikasyon riski ile ilişkili olabilir. MPV seviyesi diabetik hastalarda trombotik olayların varsayımı için kolay ve erişilebilir basit bir parametre olarak kullanılabilir.

\section{Çıkar çatışması / finansal destek beyanı}

Bu yazıdaki hiçbir yazarın herhangi bir çıkar çatışması yoktur. Yazının herhangi bir finansal desteği yoktur

\section{KAYNAKLAR}

1. Endler G, Klımesch A, Sunder-Plassmann H, et al. Mean platelet volume is an independent risk factor for mycardial infarction but not for coronary artery disease. British Journal of Haematology. 2002; 117: 399-404

2. Biadgo B, Melku M, Abebe SM, Abebe M. Hematological indices ad their correlation with fasting blood glucose level and anthropometric measurements in type 2 diabetes mellitus patients in Gondar, Northwest Ethiopia. Diabetes, Metabolic Syndrome and Obesity: Targets and Therapy 2016; 9: 91-99

3. Valencia WM, Florez $\mathrm{H}$. How to prevent the microvascular complications of type 2 diabetes beyond glucose control. BMJ 2017; 356: 6505

4. Çay S, Bıyıkoğlu F, Cihan G, Korkmaz Ş. Mean platelet volume in the patients with cardiac syndrome $X$. Journal of Thrombosis and Thrombolysis 2005; 20: 175-78

5. Abalı G, Akpınar O, Söylemez N. Correlation of the coronary severity scores and mean platelet volume in Diabetes mellitus. Adv Ther. 2014 Jan;31(1):140-8

6. Hekimsoy Z, Payzin B, Örnek T, Kandoğan G. Mean platelet volume in type 2 diabetic patients. J Diabetes Complications 2004; 18: $173-76$

7. Papanas N, Symeonidis G, Maltezos E, et al. Mean platelet volume in patients with type 2 diabetes mellitus. Platelets 2004; 15: $475-78$

8. Yenigün EC, Okyay UG, Pirpir A, Hondur A, Yıldırım iS. Increased mean platelet volume in type 2 diabetes mellitus. Dicle Medical Journal 2014; 41: 17-22

9. Ünübol $M$, Ayhan $M$, Güney $E$. The relationship between mean platelet volume with microalbuminuria and glycemic control in patents with type 2 diabetes mellitus. Platelets, September 2012; 23: 475-80

10. Jindal S, Gupta S, Gupta R, et al. Platelet indices in diabetes mellitus:indicators of diabetic microvascular complications. Hematology. 2011; 16: 86-89

11. Kebapçılar L, Bilgir O, Demirel H, ve ark. Tip2 diyabetik hastalarda ortalama trombosit volümü karşılaştırılması ve mikrovasküler komplikasyonlarla ilişkisinin değerlendirilmesi. Medical Journal of Izmir Hospital 2009; 15: 1-4 